University of Vermont

UVM ScholarWorks

College of Education and Social Services

Faculty Publications

$2-27-2013$

\title{
Early Childhood Special Education in a Refugee Resettlement Community: Challenges and Innovative Practices
}

Jennifer J. Hurley

University of Vermont, jennifer.hurley@uvm.edu

Rachel A. Warren

Rebecca D. Habalow

Lauren E. Weber

Sarah R. Tousignant

Follow this and additional works at: https://scholarworks.uvm.edu/cessfac

Part of the Early Childhood Education Commons, and the Special Education and Teaching Commons

\section{Recommended Citation}

Jennifer J. Hurley, Rachel A. Warren, Rebecca D. Habalow, Lauren E. Weber \& Sarah R. Tousignant (2014) Early childhood special education in a refugee resettlement community: challenges and innovative practices, Early Child Development and Care, 184:1, 50-62, DOI: 10.1080/03004430.2013.769214

This Article is brought to you for free and open access by the College of Education and Social Services at UVM ScholarWorks. It has been accepted for inclusion in College of Education and Social Services Faculty Publications by an authorized administrator of UVM ScholarWorks. For more information, please contact scholarworks@uvm.edu. 
Running head: REFUGEE RESETTLEMENT

Early Childhood Special Education in a Refugee Resettlement Community:

Challenges and Innovative Practices

Jennifer J. Hurley, Rachel A. Warren, Rebecca D. Habalow,

Lauren E. Weber and Sarah R. Tousignant

University of Vermont

\section{Authors Note}

Jennifer J. Hurley, Rachel A. Warren, Rebecca D. Habalow, Lauren E. Weber and Sarah R. Tousignant, Department of Education, University of Vermont.

The preparation of this manuscript was supported in part by funding from the United States Health and Human Services, Administration on Developmental Disabilities, grant award \# 90DD0645 awarded to the Center on Disability and Community Inclusion, University of Vermont. The opinions expressed herein do not necessarily reflect those of the USHHS or the Administration on Developmental Disabilities and no official endorsement should be inferred. All names have been changed to protect the confidentiality of the participants, programs, and communities.

Correspondences concerning this article should be addressed to Jennifer J. Hurley, Department of Education, University of Vermont, 537 Waterman Building, Burlington, VT 05405-0160 E-mail: jennifer.hurley@uvm.edu 
Running head: REFUGEE RESETTLEMENT

\begin{abstract}
There has been a significant increase in the number of children who are culturally and linguistically diverse (CLD) who qualify for early childhood special education (ECSE) services (Banerjee \& Guiberson, 2012). The current study investigates the challenges and innovative practices in the evaluation and (ECSE) services for preschool aged children who are refugees. Twenty-eight early childhood educators who work in a small refugee resettlement community participated in a qualitative study using semi-structured interviews resulting in themes regarding challenges and innovative practices. Challenges include: lack of validated assessments, wait time for evaluations, different cultural perspectives and family advocacy. Innovative practices include: assessing skills not dependent on language and including caregivers in evaluations. Implications for future research and teacher preparation are discussed. Keywords: Cultural and Linguistic Diversity, Early Childhood Special Education, Preschool, Qualitative, Refugee, English Language Learner
\end{abstract}


Running head: REFUGEE RESETTLEMENT

\section{Early Childhood Special Education in a Refugee Resettlement Community: Challenges and Innovative Practices}

A core value of the United States is to provide a safe haven for the oppressed and since 1975 approximately 2.6 million refugees have come to this country. In order to receive the designation of refugee, a person must belong to a race, religion, social group or have political opinions that result in well-founded fear of persecution. Many of the refugees who are relocated to the United States have experienced torture, rape, the loss of loved ones and other traumatic experiences (Office of Refugee Resettlement, 2012). The United Nations High Commission for Refugees (UNHCR) (2012) reports that 2011 was a particularly terrible year for refugees with a succession of conflicts and crisis resulting in over 800,000 refugees being forced into neighboring countries. These are the highest numbers in over a decade. The United States resettled 264,763 refugees during 2011 and the UNHCR reports that $46 \%$ of all refugees during 2011 were children under the age of 18 .

Public school in the U.S. currently have a higher level of cultural and linguistic diversity than during any other time in history and this level is expected to increase in the future (Aud et al., 2011). Ford (2012) explains that while our schools are becoming increasingly diverse it is important to note that too often children who are culturally and linguistically diverse (CLD) are viewed as a homogenous group. Ford distinguishes between children who are voluntary minorities (i.e. immigrants) and involuntary minorities (i.e. non-immigrants). For example, a child whose family is African American is considered an involuntary minority because often family members were brought to the United States in chains. In contrast to a child whose family is Hispanic whose family probably immigrated to the United States voluntarily. To take Ford's explanation of the heterogeneous nature of children who are CLD even further, the UNHRC 
Running head: REFUGEE RESETTLEMENT

explains that refugees are distinct from immigrants (i.e. voluntary minorities) in that they often have violent and tragic personal histories and rarely have the option of returning to their native country. In addition, refugees have little voice regarding the country or community that accepts them and if other countries do not afford them resettlement they will most likely experience continued extreme hardship and preventable deaths (UNHCR, 2012). Young refugee children are at risk for child mental health problems due to challenges endured by families associated with relocation including depression, poverty and difficulty in language acquisition (Morantz, Rousseau \& Heymann, 2011). While children who are refugees can be counted among the ever increasing number of children who are CLD in U.S. public schools, it is important to be mindful of how heterogeneous children and families are that share the CLD designation.

Banerjee and Guiberson (2012) explain that there has been a significant increase in young children who are CLD receiving early childhood special education (ECSE) services. As a result there is a need for ECSE service providers to adopt culturally responsive practices (Lynch \& Hanson, 2011). A recent Position Statement from the Division for Early Childhood (DEC) of the Council for Exceptional Children (2010) stressed the importance of evidence-based practices for children and families who are CLD for assessment and service delivery. There is a small but slowing growing body of evidence-based literature investigating special education services for children who are CLD. Some areas of focus include but are not limited to the history of special education services for children who are CLD (Skiba et al., 2008; Aud et al., 2011) the evaluation process for young children who are CLD (Banerjee\& Guiberson, 2012; Pavri, 2009) providing culturally responsive programs (Cartlege \& Kourea, 2008 ) collaborating with families who are CLD during Individualized Education Planning (IEP) meetings (Lo, 2008; Salas, 2004) and collaboration with interpreters during IEP meetings (Hwa-Froelich \& Westby, 2003; Otake, 
Running head: REFUGEE RESETTLEMENT

Santos \& Fowler, 2000). The purpose of this study is to explore the practices and challenges involved in evaluation and ECSE services for preschool aged children and their families who are refugees living in a small refugee resettlement community from the perspective of early childhood service providers. Given the heterogeneous nature of children who are CLD (Ford, 2012) and the lack of literature focusing specifically on evaluation and ECSE services for preschool children who are refugees, this study fills a gap in the research literature.

\section{Method}

\section{Design}

Qualitative methodology was chosen as the method for gathering evidence from early childhood service providers on the evaluation process and ECSE services in the context of a refugee resettlement community. Qualitative research is often used to shape policy and practice because it captures the perspectives of people involved in complex contexts. Qualitative methodology provides a systematic way to understand complex phenomenon and events within a particular context making it an ideal way to generate scientifically based thematic evidence and insight to better inform practice in education and provide the basis for future studies (Brantlinger, Jimenex, Klinger, Pugach \& Richardson, 2005).

\section{Settings and Participants}

Participants in this study were 28 preschool service providers working in a small New England community that between 2001 and 2011 accepted over 3,500 refugees from countries of origin including Burundi, Burma Ethiopia, Iraq, Kenya, Somalia, Sudan and more. Refugees in the community speak a variety of languages including, but not limited to Mai Mai, French, Somali, Swahili, Arabic, Vietnamese and Congolese. Participants were purposefully sampled to ensure diversity of roles: early childhood educators (ECE), early childhood special educators (ECSE), head start teachers and administrators. Participants were recruited from three 
Running head: REFUGEE RESETTLEMENT

community preschools, two Head Start Agencies, and three Local Early Childhood Special

Education Agencies. Participants were recruited from programs that varied across the following program characteristics: ratio of children being served who are refugees to children who are not, ratio of children being served who qualify for special education services to children who do not, countries of origin for the children being served, and languages spoken by the children and families. Participant demographic and program information are included in Table 1.

\section{Procedures and Data Collection}

Semi-structured interviews were conducted using an interview guide, audio-taped and transcribed verbatim. All participants were informed about procedures put in place to keep their information confidential and a signed consent was obtained from each participant. The consent form contained specific information about procedures put into place to maintain the confidentially and non-attributably of participants. Interviews were scheduled at a time and place selected by participants and included locations such as classrooms, park benches, offices and teacher's homes. The interviews were conducted by either the first author, two graduate students or one undergraduate. All students received training on administering interviews and gave practice interviews to the first author before interviewing participants. The length of interviews varied, ranging from 30 to 90 minutes. Service providers were questioned about a range of issues topics pertaining to service delivery for young children and their families who are refugees including: a) challenges or barriers to providing services, b) facilitators for providing services, c) pedagogical or intervention areas of need, d) successful classroom practices and e) the process for identifying children who may need special education services. For a copy of the interview script or the informed consent form contact the first author. After completing the interview, participants completed a demographic questionnaire. 
Running head: REFUGEE RESETTLEMENT

\section{Data Analysis}

Data were analyzed using the constant-comparative method to identify recurring themes and discover common patterns while preserving individual contextual information (Denzin, 1978; Ely, Vinz, Downing \& Anzul, 1999). Weekly lab meetings were attended by the first author, 3 graduate and 3 undergraduate students for data analysis. Students and the first author independently read the interviews a few at a time and highlighted important quotes and made lists of themes that seemed to be present across interviews. At weekly lab meetings the students would share what themes they had discovered and discussions were held until consensus was reached about what themes were present and what quotes best represented the themes by everyone at the lab meeting. Every week a few more transcribed interviews were read by everyone in the lab and the process of highlighting quotes and generate more themes to be discussed at the next lab meeting was repeated. This process continued until all of the interviews had been read and members of the lab reached consensus on a list of themes and relevant quotes. Interviews read early in this process were reread to insure that any themes or quotes missed on the first reading were found. Data reduction involved 3 undergraduate, 3 graduate students and the first author reading the transcribed interviews and looking for themes that were present across multiple interviews. After a list of themes were generated that the students and the first author agreed were present, lists of quotes supporting each theme were collected from the interviews. Finally, quotes were selected that best explained the themes and represented the sentiment of multiple participants. The first author and the students then reached consensus about what quotes best represented the themes generated. After consensus was reached about the themes and supporting quotes, the first author conducted a second level member check by providing a list of the themes and quotes to some of the participants to increase the reliability of 
Running head: REFUGEE RESETTLEMENT

the results (Brantlinger, Jimenez, Klingner, Pugach \& Richardson, 2005). After reading the themes and quotes, four ECE teachers, one administrator, and two ECSE shared with the first author that the interpretation of the data seemed accurate.

\section{Findings}

During the data reduction process it became clear that themes could be divided into two categories: 1) challenges related to the evaluation and special education services for preschool children who are refugees and 2) innovative practices being used by ECSE to overcome some of these challenges.

\section{Challenges}

\section{Obtaining screening and evaluation for preschool refugees can take years.}

Frustration was expressed by many ECE service providers about the long wait for screenings and developmental evaluations for their refugee students. As an ECE explained, "One child we felt had developmental delays. We did the referral...two years in a row! I get, 'We can't screen yet."' Another ECE said, "We have to wait till the child's proficient. Well how do you determine proficiency? Wait until the child gets in kindergarten, even though they may be three when we have them. That's a long gap." Some ECE teachers expressed anger over this issue,

I think that the special education people need to really start looking at these children as important and they need to help, some of them, and that is not just English language stuff and they need to really evaluate them... I think they are hesitant to even try and they use that they are ELL as a copout.

One ECE explained that her refugee students were not getting the same treatment as other students, 
Running head: REFUGEE RESETTLEMENT

I mean, there has to be something for kids that are in this country and don't speak the language who we suspect may have a delay. Why wait just because they don't speak our language? They're in this country and they're in our schools, so we have to do whatever we can to provide them the same services as we would any other child in our school. Another ECE commented that the frustration was also shared by some of the refugee families, “The mother says, 'Well, why don't they, you said my child has a problem, you said my child has a problem! Why aren't they getting services? ... Now why isn't (local early childhood special education agency) going to help us?"”

Many ECSE service providers explained the need to "wait and see" rather than provide the screening and assessment process typically used to determine eligibility for special education services, "We would at least look at that child; get a baseline of their skills, and then two years down the road to see what progress is in terms of English language learning." In the words of another ECSE, "We're not looking to make kids eligible for special education if they don't need it." One ECSE indicated that the refugee children experiencing difficulty might be better served by educators in other roles, "I am a special educator. I am not an ELL (English Language Learner) specialist."

\section{Lack of validated assessment tools for many of the refugee cultures in the}

\section{community.}

A significant challenge for the service providers in this refugee community is that while screening tools and developmental evaluations have been translated into many languages and are available through the Culturally and Linguistically Appropriate Services web site (CLAS, 2010), there are no tools that have been translated into many of the languages (e.g. Maay Maay, Somali, Swahili and Congolese) spoken by the families in this community. This is further complicated by 
Running head: REFUGEE RESETTLEMENT

the lack of a written version for some of the languages spoken and a lack of trained service providers who can speak the languages while administrating the assessments. This leaves ECSEs without the technology typically employed to determine if a child needs special education services. One ECSE explained, "There isn't anything standardized we can use for ELL students.” Some ECSE teachers expressed concern that cultural differences and language barriers have affected the test results for some refugee children, "We feel that part of the testing did not take into account that she was an English language learner. She had received a diagnosis of Autism Spectrum Disorder complicated by not only her understanding of the English language but also some cultural differences as well."

\section{Teachers perceive some refugee families as not being able to advocate for special}

\section{education services for their children.}

Some ECE teachers expressed concern that refugee families were not in a position to complain when their children did not get special education services. One ECE teacher said, "I know it is hard for the parents because they are trying to fit in, which is the hard part, so they don't complain." Another ECE teacher further explained,

Pushy parents. If you have a parent who has the ability to reach out and ask and demand and persevere they are going to get it (special education services).... It is like a squeaky wheel syndrome, and that, unfortunately, when you are in a new culture it is like the opposite of what you feel like you can do.

Another ECE teacher added that some families may be afraid to ask for services, "Asking for help for a service that you have no experience with because it's not available in your country. I think there's a fear factor that goes with that along with a lack of comfort." One ECSE teacher described how past traumatic experiences can impact a families ability to advocate, "We've had 
Running head: REFUGEE RESETTLEMENT

a lot of helplessness. There is some major post-traumatic stress in the family and that has been a huge challenge and barrier too."

\section{Families and teachers often have different perspectives on special education}

\section{services, disability and how best to help children.}

Participants expressed concern about how some refugee families perceived their children after being informed about their child's disability. One ECE teacher lamented that after being told their child qualified for special education services, "His parents said, 'My child he is crazy in the head." Another ECE teacher explained that given the context of experiences the refugee families have been through, the need for special education services may not be a top priority, Not just a language barrier, but also a barrier around priorities... what is important to the parents and what's important to us...Their life experiences are so different ... and truly unimaginable. So when we have a concern about speech not coming along or behavioral challenges, their responses are sometimes almost, 'what is the big deal here?' Our life experiences and expectations and goals and hopes for children are just sometimes at a very different place.

One ECSE teacher described the cultural divide that can exist between families and professionals,

There is miscommunication and cultural divide between what you want and value and what the family does, and what the school policies are on special education placement... things we identify as being a need, they don't think is a need.

An ECSE teacher explained that getting some refugee families through the series of assessments, meetings and paperwork necessary to initiate special education services is often challenging, "It 
Running head: REFUGEE RESETTLEMENT

was difficult for them to see any need to have to come to school to qualify for what in their mind was unnecessary (special education services).”

Disconnect between the perspective of one refugee family and their ECSE provider is illustrated in this quote from an ECSE teacher,

The family didn't have full appreciation for why it was significant for him to have this operation (surgical implant of an electronic assistive technology device) or not. ...coming from a refugee camp, they had no understanding, 'Allah created him the way he is and we had no right in trying to fix it,'...they don't fully appreciate the impact of the decision that they are being asked to make.

\section{Innovative Practices}

Despite the challenges involved in determining service eligibility for young children who are CLD and refugees, some of the ECSE teachers described the innovative methods they are using to try to determine if a child should receive special education services and about some situations where eligibility determination is clearer.

\section{Development can be assessed by examining play.}

One ECSE teacher explained the value of observing a child during play and social interactions, "You can tell a lot through children's play skills or just through their attention and how they interact with people and how they interact with materials and at least get a ballpark." Another ECSE teacher explained, "It is easier to target her because she has, what I suspect, is gross motor. So you can get at that through play and being active, I would feel a lot more stuck if it were a cognitive delay of some kind."

\section{Development can be assessed by asking caregivers about how the child is doing in}

\section{their native language.}


Running head: REFUGEE RESETTLEMENT

Some ECSE teachers explained that by using an interpreter to talk with the families about how a child is doing in the context of their own home and in their native language they could get information about how a child is developing. One ECSE teacher stated, "We met with the parents and talked with the parents about what they thought about what was going on at home when they are speaking their traditional language at home if they see a delay in things."

\section{Development can be assessed by comparing development between siblings.}

When talking to families about their child's development some ECSE teachers ask families to compare the development of the child in question with the development of a sibling, "Hopefully, there is a sibling by which to help the parent evaluate their child's development...of course that is not standardized." One ECSE teacher recalled the benefit of comparing development between twins, "Because she had a twin who was typically developing, you could look at the two and see that there was a dramatic difference."

\section{Refugee preschoolers with delays in motor development are easier to evaluate for} special education services.

One ECSE teacher explained that if a child had a disability that was visible then eligibility for special education services was easier to determine,

She had trouble with one leg shorter than the other. That particular child it was much easier to be able to look at her needs in terms of special education because first of all you didn't have to speak English to have a motor disability.

Another ECSE teacher described how motor delays were easier to identify, "We can't qualify them under speech. Lots of times its motor delays." One ECSE teacher explained, "I would be concerned with gross motor, which transcends language. So I would just by using my observation, I could tell that is something that you don't need language to ascertain." 
Running head: REFUGEE RESETTLEMENT

\section{Discussion}

The results of this study illuminate several phenomena of relevance for the service of young refugee children who may be experiencing disability in a small New England community. This study highlights irritation among ECE service providers who explained that refugees are not getting the same evaluation as promptly as other preschool aged children with suspected delays. In the words of one ECE teacher,

The biggest problem is that the organization (local early childhood special education agency) dismisses the fact that these kids could have needs and they are looking at well they don't speak English yet so that's the only problem and we can't test them until they start speaking English...Just because they don't speak English doesn't mean that they don't need extra help too.

Simultaneously the ECSE teachers are frustrated because of the multiple challenges inherent in providing an assessment to a child when the assessment tools typically used are potentially biased due to cultural and linguistic demands, "We cannot assess whether there is a delay because of the language barrier."

The challenge of identifying students who are CLD in need of special education services is not unique to this community. Parvi (2009) explains that it is difficult for teachers to discern between delayed development and cultural difference. Eligibility determination is children and families who are CLD is further complicated by test bias and language barriers (Abedi, 2004; Banerjee \& Guiberson, 2012; Skiba et al., 2008). The service providers in the current study do not have access to assessment tools that have been translated into many of the relevant languages. Translation is particularly daunting for languages such as Maay Maay for which there is no written system. Even if an assessment is translated, there are concerns regarding bias in the 
Running head: REFUGEE RESETTLEMENT

very process of assessment and in the test items themselves (Banerjee \& Guiberson; Valencia \& Suzuki, 2000). Bias threatens the validity of an assessment when it is used on a child whose cultural group was not included in the validation of the assessment tool. Cultural bias can be present when children are assessed using activities that are uncommon in the child's culture (Banerjee \& Guiberson).

ECSE service providers expressed dismay that, “There isn't anything standardized we can use for ELL students." Despite these challenges, ECSE participants shared several innovative and promising strategies they have employed: a) assessing domains of development not dependent on language (e.g. motor development), b) observing the child in play, c) questioning the family about language development in their native language, and d) comparing the child's development to siblings or children who have similar backgrounds. As one of the ECSE teachers pointed out, "of course that is not standardized." However, the assessment strategies reported by ECSE providers in the current study echo some of Banerjee and Guiberson's (2012) recent recommendations for the assessment of children who are CLD. For example, including families as a source of information when determining eligibility and assessing children through play. In addition, the strategies shared from some of the ECSE participants mirror the suggestions from Position Statement from the Division for Early Childhood (DEC, 2010). For example, ECSE service providers reported the benefits of including families in the assessment process and described strategies for individuating assessments for particular families (e.g. ECSE participants reported comparing a child's development to that of a sibling if there was one available).

One strategy for including families in the assessment process that Banerjee and Guiberson (2012) argue provides important information and can help ensure the evaluation 
Running head: REFUGEE RESETTLEMENT

process is more culturally relevant for a family is to make use of the Routines Based Interview Report Form (RBI) developed by McWillam (2006). ECSE service providers in the current study already report gathering information from families during the assessment process. The benefit of adopting the RBI report form is that it would provide ECSE providers with a structured report allowing families to contribute valuable information about their child's development across multiple developmental domains (i.e. physical, cognitive, communication, social or emotional and adaptive) as demonstrated within the culturally relevant routines of the family. Completing a form to document a family's daily routines including descriptions of their child's engagement and level of independence in these routines facilitates the gathering of detailed culturally relevant assessment information. In addition, the format of the RBI report form provides an opportunity for the family to generate areas of concern and share the developmental priorities they have for their child. The administration of the RBI report form (Banerjee \& Guiberson; McWilliam), combined with observations of children in their natural environments engaging with family members in daily routines (Jackson, Pretti-Frontczak, Harjusola-Webb, Grisham-Brown, \& Romani, 2009) provides culturally relevant information to inform decisions regarding eligibly and program planning and includes families in the process.

Participants in the current study expressed concern that families were not in a position to advocate for ECSE because of fear, lack of comfort or that as newly resettled refugees they are, “trying to fit in ... so they don't complain.” Similarly, Mole (1993) found that immigrant families experience discomfort and fear when visiting their children's schools. Studies investigating to role of families who are CLD during IEP meetings revealed that families can be overwhelmed by language barriers and too much information (Lo, 2008) or confused about how the educational system in the United States works (Salas, 2004). The disenfranchisement of 
Running head: REFUGEE RESETTLEMENT

refuge or other CLD families from the assessment or program planning process for special education services is a distinct barrier to the collaborative partnership described in the DEC Position Statement (DEC, 2010). Efforts should be made to discover what practices could be put into place to make families feel more confident and less fearful when going through the evaluation process or participating in their children's educational programs.

In addition to the challenge described by participants in the current study, identification of preschool refugees in need of special education is further complicated by the history of CLD student overrepresentation in self-contained classes and the disproportionate over use of the label mentally retarded for minority children (Ford, 2012; Skiba et al., 2008). Awareness of this injustice may contribute to the belief voiced by many ECSE teachers in the current study that, "It is better to wait and see...we shouldn't be too quick to say that they need special education."

Despite the history of overrepresentation of CLD students in special education and the difficulties in proper identification, Cartledge and Kourea (2008) stress that interventions need to be implemented as early as possible for students who are CLD, particularly during the preschool years. This view is shared by some of the ECE participants, "The whole point of it is to get in there early! That's the point of the program. Why wait just because they don't speak our language?" Many ECE participants voiced concerns that the pendulum has swung back in the direction of underserving children who are CLD and sentiment expressed, "We need help!" was shared by many ECEs. Ford's (2012) article discusses the overrepresentation of children who are CLD in special education and provides the important caution that yes, special education services are helpful, but when services are inappropriate the educational system and students suffer. Ford's sentiment in combination with the challenges discussed regarding the evaluation of children who are CLD may provide the rationale for the ECSE participants who explained, 
Running head: REFUGEE RESETTLEMENT

"We're not looking to make kids eligible for special education if they don't need it." The challenges and conflicts raised by the participants in this study are complicated and elicit a range of emotions and given the demographic trends in the U.S., show no sign of going away (Aud et al., 2011).

\section{Limitations of the Present Study}

One obvious limitation of the current study is the lack of refugee family members included as participants. All of the themes about evaluation and ECES services were generated by service providers. The perspective of the families receiving these services would provide valuable insight and feedback about what is working and where improvements are needed. Another limitation of the current study is the small sample size and that all participants were recruited from the same small New England community. The themes generate in the current study cannot be generalized to other settings but may still be useful given the shortage of research on early childhood education services for young refugee children and their families. It is important to note, however, that the purpose of qualitative research is not to generalize to other settings and people but to produce evidence based on the investigation of a particular context (Brantlinger, Jimenez, Klingner, Pugach \& Richardson, 2005).

\section{Conclusions and Future Prospects}

Ford and colleagues (2012) explains that while the number of children we serve from non-English speaking homes continues to rise, the majority of the service providers come from the dominant Euro-American culture. Arguably one of the most direct routes to making ECSE services and the evaluation process more culturally appropriate is to include service providers from the cultures and communities receiving services. Eighty-five percent of all teachers in U.S. public schools (Aud et al., 2011) and 96\% of the educators in the current study identify as white. 
Running head: REFUGEE RESETTLEMENT

Colleges and universities with teacher preparation programs must actively recruit and retain teacher candidates who are themselves CLD and or refugees.

Given that we know cultural dissonance between the home and school is a contributor to poor educational outcomes (Cartledge \& Kourea, 2008), we must make the development and support of cultural competence a higher priority in teacher preparation programs (Hurley, Stewart \& Cohn, 2011). At a minimum, educators should be taught to respect, include and value the voices of families whose culture may dictate a very different set of values from that of the dominant culture. For example, teachers must learn to respect families who reflect on the "Will of Alah," when deciding how best to intervene on their child's behalf even if the "Will of Alah," is of no concern to the teacher. Evaluation practices and ECSE services need to be examined through the lens of the cultures we serve. Only by listening to the voices of refugee families can we learn how to provide more culturally sensitive services.

With the reauthorization of Individuals with Disabilities Education Improvement Act (IDEA, 2004), families were given an even more important role in the assessment and program planning process and are seen as equal partners with the school. The Office of Refugee Resettlement's mission statement explains that refugees are able members of our society who bring with them capabilities to contribute (2012). Like all families, refugee families should be acknowledged as being the experts regarding their child's needs, daily routine and strengths. Lo (2008) explains that without the input of CLD families, schools may have difficulty providing an appropriate program. This study has highlighted some of the current innovative practices being implemented by early childhood educators in a refugee resettlement such as including families in the evaluation process. The adoption of McWillam's (2006) RBI is one strategy as suggested by Banerjee and Guiberson (2012) would be one evidence-based practice that would build on the 
Running head: REFUGEE RESETTLEMENT

innovative strategies currently being used by ECSE. Developing more evidence-based practices

for including refugee families in the evaluation process and for making that process more culturally relevant is essential.

The UNHCR's (2012) annual report on global trends describes 2011 as a year of crises with the highest number of displaced refugees, almost half of them children, in over a decade and the high numbers of children in U.S. schools who are CLD is predicted to have continued growth (Aud et al., 2011). It is becoming clear that the skills and dispositions necessary for collaboration with children and families who are CLD cannot remain the exclusive domain of professionals with ELL endorsements. The opinion that, "I am a special educator, I am not an ELL specialist," has become outdated and insufficient. Evidence-based practices must continue to be developed, adopted and implemented by ECSE professionals for serving families and children who are refugees or CLD so that we can make our schools reflect the core value of our country and truly become safe havens for the oppressed. 
Running head: REFUGEE RESETTLEMENT

\section{REFERENCES}

Abedi, J. (2004). The No Child Left Behind Act and English language learners: Assessment and accountability issues. Education Researcher, 33 (1), 4-14.

Aud, S., Hussar, W., Kena, G., Bianco, K., Forhlich, L., Demp, J., . . Hannes, G. (2011, May). The condition of education 2011 (NCES 2011-033). Washington, DC: U.S. Department of Education, National Center for Education Statistics. Retrieved from http://nces.ed.gov/pubs2011/2011033.pdf

Banerjee, R. \& Guiberson, M. (2012). Evaluating young children from culturally and linguistically diverse backgrounds for special education services. Young Exceptional Children, 15 (1), 33-44.

Brantlinger, E., Jimenez, R., Klingner, J., Pugach, M. \& Richardson, V. (2005). Qualitative studies in special education. Exceptional Children, 71 (2) 195-207.

Cartledge, G., \& Kourea, L. (2008). Culturally responsive classrooms for culturally diverse students with and at risk for disabilities. Exceptional Children, 74, 351-371.

Culturally and Linguistically Appropriate Services (2012). Urbana-Champaign, Illinois Retrieve August 1, 2012: http://clas.uiuc.edu/special/evaltools/index.html

Denzin, M. K. (1978). The research act: An introduction to sociological methods. New York: McGraw Hill.

Division for Early Childhood of the Council for Exceptional Children. (2010). Responsiveness to ALL children, families, and professionals: Integrating cultural and linguistic diversity into policy and practice (Position Statement). Missoula, MT: Author. Retrieved from http://www.dec-sped.org/uploads/docs/about_dec/position_concept_papers/Position\% 20Statement_Cultural\%20and\%20Linguistic\%20Diversity_updated_sept2010.pdf 
Running head: REFUGEE RESETTLEMENT

Ely M., Vinz, R., Downing, M., \& Anzul, M. (1999). On Writing Qualitative Research: Living by Words. Washington, DC. The Falmer Press.

Ford, D. Y. (2012). Culturally different students in special education: Looking backward to move forward. Exceptional Children, 78 (4), 391-405.

Hwa-Froelich, D. A., \& Westby, C. e. (2003). Considerations when working with interpreters. Communication Disorders Quarterly, 3 (31) 78-85.

Hurley, J. J., Stewart, E. Medici, A. \& Cohn, Z. (2011). Supporting preschoolers and their families who are recently resettled refugees. Multicultural Perspectives, 13 (3), 160-166. doi: $10.1080 / 15210960.2011 .594400$

Individuals with Disabilities Education Act Amendments of 2004. (2004). U.S.C. sec. 1400 et $\operatorname{seq}(2001)$

Jackson, S., Pretti-Frontczak, K., Harjusola-Webb, S., Grisham-Brown, J., \& Romani, J. M. (2009). Response to intervention: Implications for early childhood professionals. Language, Speech, and Hearing Services in Schools, 40, 424-434.

Lo, L. (2008). Chinese families' level of participation and experiences in IEP meetings. Prevention School Failure, 53 (1) 21-28.

Lynch, W. W. \& Hanson, M. J. (Eds.). (2011). Developing cross-cultural competence: Working with young children and their families ( $4^{\text {th }}$ ed.). Baltimore, MD: Paul H. Brookes.

McWilliam, R. A. (2006). Routines-based interview report form (Vanderbilt Center for Child Development). Retrieved from http://www.siskin.org/downloads/RBI_Report_Form.pdf Mole, O. C. (1993). Collaboration between schools and disadvantaged parents: Obstacles and openings. In N. F. Chavkin (Ed.), Families and Schools in a Pluralistic Society (pp. 2147). Albany, NY: SUNY Press. 
Running head: REFUGEE RESETTLEMENT

Morantz, G., Rousseau, C., \& Heymann, J. (2011). Caring for migrant refugee children:

Challenges associated with mental health care in pediatrics. Journal of Developmental and Behavioral Pediatrics, 27 (2), 145-154.

Office of Refugee Resettlement. (2012). U.S. Department of Health and Human Services, Administration for Children and Families. Washington, D. C. Retrieved August 1, 2012 from http://www.acf.hhs.gov/programs/orr/about/mission.htm

Ohtake, Y. S., Santos, R. M. \& Fowler, S. A. (2000). It's a three-way conversation: Families, service providers and interpreters working together. Young Exceptional Children, 4 (1) $12-18$.

Pavri, S. (2009). Developmental delay or cultural difference? Young Exceptional Children, 4 (4), $2-9$.

Salas, L. (2004). Individualized education plan IEP meetings and Mexican American parents: Let's talk about it. Journal of Latinos and Education, 3 (3) 181-192.

Skiba, J. R., Simmons, A. B, Ritter, S., Gibb, A. C. Rausch, M. K., Cuadrado, J. \& Chung, C. G. (2008). Achieving equity in special education: History, status, and current challenges. Exceptional Children, 74 (3), 264-288.

United Nations High Commission for Refugees (2012). A year of crisis: UNHRC global trends 2011- The U.N. Refugee Agency website. Geneva, Switzerland. Retrieved July 29, 2012: http://www.unhcr.org/4fd6f87f9.html

Valencia, R. R., \& Suzuki, L. A. (2000). Intelligence testing and minority students: Foundations, performance factors, and assessment issues. Thousand Oaks, CA: Sage. 
Running head: REFUGEE RESETTLEMENT

Table 1

Participant Demographic Information

$\begin{array}{lll}\text { Characteristic } & N & \text { Percent }\end{array}$

Sex

Male

2

$7.14 \%$

Female

26

$92.86 \%$

Race/Ethnicity

White, non-Hispanic

27

$96.43 \%$

Latin or Hispanic

1

$3.57 \%$

Education

High school

1

$3.57 \%$

Bachelor's degree

16

$57.14 \%$

Master's degree

10

$35.71 \%$

Doctorate/JD/MD/etc.

1

$3.57 \%$

Job

ECE

12

$42.86 \%$

ECSE

7

$25.00 \%$

Administrator

6

$21.43 \%$ 